\title{
ÉPOCA REPRODUTIVA DO CAMARÃO BRANCO LITOPENAEUS SCHMITTI EM LUCENA, LITORAL NORTE DA PARAÍBA
}

\author{
Silva, E.F.B.. ${ }^{1 *}$; Craveiro, C. ${ }^{2}$; Gonzalez, E. ${ }^{1}$; Lima, Y.G.S. ${ }^{1}$; Nolé, L. ${ }^{3}$; Lira, A.S. ${ }^{3}$; \\ Castro Neto, H. ${ }^{2}$; Lucena, F. ${ }^{3}$; Peixoto, S. $^{2}$ \& Soares, R. ${ }^{2}$ \\ ${ }^{1}$ Instituto Federal de Educação, Ciência e Tecnologia da Paraíba (IFPB), Campus Cabedelo. \\ Laboratório de Oceanografia. \\ ${ }^{2}$ Universidade Federal Rural de Pernambuco (UFRPE), Campus Recife. Laboratório de Tecnologia \\ em Aquicultura (LTA). \\ ${ }^{3}$ Universidade Federal Rural de Pernambuco (UFRPE), Campus Recife. Laboratório de Estudos de Impactos \\ Antrópicos na Biodiversidade Marinha e Estuarina (BIOIMPACT). \\ *Autor correspondente: emanuellfelipe@yahoo.com.br
}

O camarão branco Litopenaeus schmitti é a espécie de peneídeo com maior valor econômico entre as espécies capturadas no Município de Lucena, litoral norte da Paraíba. Nesse sentindo, a determinação do seu período reprodutivo é de fundamental importância para auxiliar na regulamentação da sua captura. Informações acerca dos aspectos reprodutivos dessa espécie na região é incipiente. Dessa forma, objetivou-se com o presente estudo determinar a época reprodutiva do camarão L. schmitti em Lucena, litoral norte da Paraíba. Os camarões foram coletados mensalmente, de dezembro de 2016 a novembro de 2017, através da pesca artesanal utilizando um arrastão de praia com auxílio de uma canoa, uma vez que esta é a modalidade de pesca predominante na região para captura de camarões. Para as fêmeas, a proporção dos estágios de maturação gonadal foi determinada por mês através da classificação macroscópica e/ou microscópica do ovário, com o objetivo de determinar a época reprodutiva. Um total de 1.710 espécimes foram coletados, correspondendo a 966 fêmeas e 744 machos, representando uma proporção de $56,49 \%$ e $43,51 \%$, respectivamente. Do total de fêmeas capturadas, $22,51 \%$ encontravam-se imaturas, 12,55\% em maturação inicial, 13,38\% em maturação avançada, 3,54\% maturas e $48,02 \%$ desovadas. De acordo com a distribuição dos estágios de maturação gonadal, não foram observadas fêmeas em maturação (inicial ou avançada) ou maturas nos meses de julho e agosto, entretanto, fêmeas maturas foram observadas de outubro a março, com picos reprodutivos em novembro e fevereiro, correspondendo a $9,28 \%$ e $33,33 \%$ do total de fêmeas maturas, respectivamente. Nesse contexto, a reprodução do L. schmitti em Lucena ocorre nos meses mais quentes do ano e a intensificação das chuvas pode ser considerada um fator determinante para a redução da atividade reprodutiva da espécie na região estudada.

Palavras-chave: peneídeos, pesca, maturação gonadal, reprodução. 